\title{
Biomass and distribution of the red octopus (Octopus maya) in the northeast of the Campeche Bank
}

\begin{tabular}{|c|c|}
\hline Journal: & Journal of the Marine Biological Association of the United Kingdom \\
\hline Manuscript ID & JMBA-01-19-OA-0016.R1 \\
\hline Manuscript Type: & Original Article \\
\hline $\begin{array}{r}\text { Date Submitted by the } \\
\text { Author: }\end{array}$ & 22-Mar-2019 \\
\hline Complete List of Authors: & $\begin{array}{l}\text { Avendaño, Otilio; Centro de Investigación y de Estudios Avanzados del } \\
\text { Instituto Politécnico Nacional, Unidad Mérida, Recursos del Mar; } \\
\text { Universidad de Ciencias y Artes de Chiapas, Tonalá, Chiapas, C.P. 30500, } \\
\text { México } \\
\text { Velázquez-Abunader, Iván; Centro de Investigación y de Estudios } \\
\text { Avanzados del Instituto Politécnico Nacional, Unidad Mérida } \\
\text { Fernández-Jardón, Carlos; Facultad de Ciencias Económicas y } \\
\text { Empresariales, Universidad de Vigo, C.P. } 36310 \\
\text { Ángeles-González, Luis; Universidad Nacional Autónoma de México. } \\
\text { Sisal, Yucatán, C.P. 97356, México } \\
\text { Hernández-Flores, Alvaro; 5Universidad Marista de Mérida, Periférico } \\
\text { norte tablaje catastral 13941, Carretera Mérida-Progreso. C.P. } 97300 \\
\text { Mérida, Yucatán, México } \\
\text { Guerra, Angel; Instituto de Investigaciones Marinas (CSIC), Ecology and } \\
\text { Marine Resources }\end{array}$ \\
\hline Keywords: & $\begin{array}{l}\text { Octopus maya, Red octopus, Spatial, Density, Abundance, Continental } \\
\text { shelf, Yucatán }\end{array}$ \\
\hline Abstract: & $\begin{array}{l}\text { The regulatory framework of the red octopus (Octopus maya) fishery } \\
\text { includes total allowable catches (TAC), which are based on studies } \\
\text { conducted on the population that occurs in shallow waters. In fact, most } \\
\text { of the biological studies of this species refer to the fraction of the } \\
\text { population that occupies waters less than } 30 \text { m deep; however, } O \text {. maya } \\
\text { can occur up to a } 60 \mathrm{~m} \text { depth. The aim of this study is to assess the } \\
\text { stock of } O \text {. maya that occupies waters between } 30 \mathrm{~m} \text { and } 60 \mathrm{~m} \text { deep. } \\
\text { Four research cruises were carried out during the closed and fishing } \\
\text { seasons, from May } 2016 \text { to January } 2017 \text {. An average of } 29 \text { sampling } \\
\text { sites were surveyed in each cruise ( } \pm 2 \text { sampling sites) using a } \\
\text { commercial vessel with a uniform sampling effort. In each sampling site, } \\
\text { the swept area, the total number of octopuses captured, the total weight } \\
\text { of the catch, and the individual weight of octopuses were recorded. } \\
\text { Biomass was obtained with four methods: stratified random method, } \\
\text { swept area method, geo-statistical biomass model, and an unpublished } \\
\text { method of weighted swept area. The four methods provided consistent } \\
\text { results. The distribution pattern of species was in patches, although } \\
\text { before the fishing season started it was more homogeneous. The fraction } \\
\text { of the population that occurs between } 30 \text { m and } 60 \mathrm{~m} \text { deep consisted } \\
\text { mostly of adult organisms, so it could be contributing significantly to the } \\
\text { recruitment of the entire population, even to the fraction that is } \\
\text { exploited. }\end{array}$ \\
\hline
\end{tabular}




\section{SCHOLARONE ${ }^{\text {m }}$ \\ Manuscripts}


1 Running head: Biomass and distribution of Octopus maya

2 Biomass and distribution of the red octopus (Octopus maya) in the northeast of the

\section{Campeche Bank}

4 Otilio Avendaño ${ }^{1,2}$, Iván Velázquez-Abunader ${ }^{1}$, Carlos Fernández-Jardón ${ }^{3}$, Luis Enrique

5 Ángeles-González ${ }^{4}$, Alvaro Hernández-Flores ${ }^{5}$ and Ángel Guerra ${ }^{6}$

$6 \quad{ }^{1}$ Centro de Investigación y de Estudios Avanzados del IPN, CP 97310, Mérida, Yucatán,

7 México, ${ }^{2}$ Universidad de Ciencias y Artes de Chiapas, Tonalá, Chiapas, C.P. 30500,

8 México, ${ }^{3}$ Facultad de Ciencias Económicas y Empresariales, Universidad de Vigo, C.P.

9 36310, Vigo, España, ${ }^{4}$ Universidad Nacional Autónoma de México. Sisal, Yucatán, C.P.

10 97356, México, ${ }^{5}$ Universidad Marista de Mérida, Periférico norte tablaje catastral 13941,

11 Carretera Mérida-Progreso. C.P. 97300 Mérida, Yucatán, México and ${ }^{6}$ ECOBIOMAR,

12 Instituto de Investigaciones Marinas (IIM-CSIC), C.P. 36208, Vigo, España.

\section{Author for correspondence:}

14 Iván Velázquez-Abunader, E-mail: jvelazquez@cinvestav.mx 


\section{Abstract}

16 The regulatory framework of the red octopus (Octopus maya) fishery includes total

17 allowable catches (TAC), which are based on studies conducted on the population that

18 occurs in shallow waters. In fact, most of the biological studies of this species refer to the

19 fraction of the population that occupies waters less than $30 \mathrm{~m}$ deep; however, O. maya can

20 occur up to a $60 \mathrm{~m}$ depth. The aim of this study is to assess the stock of $O$. maya that

21 occupies waters between $30 \mathrm{~m}$ and $60 \mathrm{~m}$ deep. Four research cruises were carried out

22 during the closed and fishing seasons, from May 2016 to January 2017. An average of 29

23 sampling sites were surveyed in each cruise ( \pm 2 sampling sites) using a commercial vessel

24 with a uniform sampling effort. In each sampling site, the swept area, the total number of

25 octopuses captured, the total weight of the catch, and the individual weight of octopuses

26 were recorded. Biomass was obtained with four methods: stratified random method, swept

27 area method, geo-statistical biomass model, and an unpublished method of weighted swept

28 area. The four methods provided consistent results. The distribution pattern of species was

29 in patches, although before the fishing season started it was more homogeneous. The

30 fraction of the population that occurs between $30 \mathrm{~m}$ and $60 \mathrm{~m}$ deep consisted mostly of

31 adult organisms, so it could be contributing significantly to the recruitment of the entire

32 population, even to the fraction that is exploited.

33 Key words: Octopus maya, Red octopus, spatial, density, abundance, continental shelf, 34 Yucatán. 
36 The octopus stocks that occupy the western and northern coasts of Yucatan Peninsula are

37 considered by far one of the most important resources for small-scale fishers from Mexico

38 due to its high productivity, economic value and international demand (Cabrera-Vázquez et

39 al., 2012). Records show that two species are exploited namely red octopus, Octopus maya,

40 Voss \& Solís-Ramírez, 1966 and the common octopus, O. "vulgaris” type I (Cuvier, 1797;

41 Jereb et al., 2014). However, new studies suggest that the latter corresponds to $O$. insularis

42 (Lima et al., 2017).

43 O. maya contributes more than $60 \%$ to the fishing production of octopus in the

44 region (Velázquez-Abunader et al., 2013). It is an endemic species of the continental shelf

45 of the Yucatan Peninsula. Although it has been observed to be abundant both in shallow (<

$4630 \mathrm{~m}$ ) and deeper waters (up to $60 \mathrm{~m}$ ), but more abundant in shallow waters (DOF, 2016).

47 The species displays a heterogeneous distribution, having the greatest abundance in the

48 coasts in front of the State of Campeche, predominantly composed of small individuals,

49 while the largest individuals are found in front of the State of Yucatan (Cabrera-Vázquez et

50 al., 2012; Gamboa-Álvarez et al., 2015). A more recent study suggests that perhaps two

51 closely related sub-stocks of $O$. maya exist in the region: the first occupies the western

52 coast of the Yucatan Peninsula, where reproduction exhibits a clear seasonality with a peak

53 during the winter and, a second stock located at the north of the Yucatan peninsula, where

54 spawners can be found all year round (Ángeles-González et al., 2017).

55 The most recent stock assessment indicates that $O$. maya is exploited at the

56 "maximum level" (i.e. close to the maximum sustainable yield) with annual landings of 
57 more than 10,000 tones (Jurado-Molina, 2010). In order to maintain production levels, the

58 authority established the minimum legal size of $11 \mathrm{~cm}$ mantle length, a closed fishing

59 season (from January to July), and total allowable catch (TAC). The TAC is obtained from

60 biomass estimations using surplus production models based on the catch landings reports

61 (DOF, 2016).

Octopus maya is captured by two fleets: a small-scale fleet (boats of 5 to $12 \mathrm{~m}$

63 length) that operates in shallow waters (up to $20 \mathrm{~m}$ depth) and a medium-scale fleet (boats

64 from 15 to $25 \mathrm{~m}$ length) that operates in areas deeper than $20 \mathrm{~m}$. Both fleets use small boats

$654 \mathrm{~m}$ in length (locally known as "alijos") which are drifted by the currents to catch octopus

66 (Salas et al., 2008). These fleets use the same fishing gears and operate in different fishing

67 grounds but sometimes overlap due to the accessibility and high abundance of the resource

68 in those areas (Salas et al., 2008; Gamboa-Álvarez et al., 2015). Likewise, as a result of

69 easy access and low monitoring costs, most of the studies on biology and stock assessment

70 for 0 . maya refers to animals found in the shallow waters of those fishing grounds $(<30 \mathrm{~m})$

71 (Cabrera-Vázquez et al., 2012; Velázquez-Abunader et al., 2013; Avila-Poveda et al.,

72 2016; Ángeles-González et al., 2017; Duarte et al., 2018), however, producing a dearth of

73 information on the fraction of the population that occupies areas from $30 \mathrm{~m}$ to $60 \mathrm{~m}$ depth.

74 The private sector of Mexico has expressed its intention to expand the fishing grounds for

75 the medium-scale fleet to deeper waters in view to its economic importance (DOF, 2016). It

76 is for that reason that the objective of this study is to evaluate the available biomass of $O$.

77 maya and learn more about its distribution in coastal areas in the Campeche Bank where the

78 depth is between $30 \mathrm{~m}$ and $60 \mathrm{~m}$, to provide basic information for its management. 


\section{Material and methods}

\section{$80 \quad$ Study area}

81 The study area, known as the Campeche Bank, is located in the coastal zone at the northeast

82 of the Yucatan Peninsula, between $30 \mathrm{~m}$ and $60 \mathrm{~m}$ depth (Figure 1). The area is strongly

83 influenced by the Yucatan current, which produces a stationary upwelling, from May to

84 September, but there is vertical mixing during winter due to strong north winds from $70 \mathrm{~km}$

$85 \mathrm{~h}^{-1}$ to more than $100 \mathrm{~km} \mathrm{~h}^{-1}$ (from October to January) (Enriquez et al., 2010; Salas-Pérez et

$86 a l ., 2012)$. The average temperature is $20^{\circ} \mathrm{C}$ but and a range of $17^{\circ} \mathrm{C}$ to $30^{\circ} \mathrm{C}$. The

87 upwelling enhances the concentration of nutrients resulting in a high biological

88 productivity.

\section{Field work}

90 Four research cruise ships independent of the fishery were conducted from May 2016 to

91 January 2017. Each cruise was made on board of a vessel of the medium-scale fleet with

92 landing port in Progreso, Yucatan. An average of $29( \pm 2)$ sampling sites were surveyed per

93 cruise ship; the distance between sampling sites was $28 \mathrm{~km}$ in May-June, and $14 \mathrm{~km}$ in the

94 other cruises (Figure 1). Sampling sites were systematically aligned in the study area, using

95 spsample function of $s p$ package (Pebesma \& Bivand, 2005) of the programming language

96 R (R Core Team, 2017). During the season closed for fishing, two cruises were carried out,

97 May-June 2016 and July 2016, just when the fishing seasons started. Two additional cruises

98 were placed on December 2016 and January 2017, to represent the end of the fishing

99 season. 
The survey and collection of organisms were done through regular fishing

101 operations. The vessel was a mother ship of five "alijos" (4 $\mathrm{m}$ length); each carrying two

102 rustic poles made of bamboo of approximately $8 \mathrm{~m}$ length, one in the bow and other in the

103 stern of the boat. Each pole had 2 nylon lines tied with fishes (Diplectrum sp and Haemulon

$104 s p$.) as bait, which were dragged at the sea floor as the boat drifted at sea (Jurado-Molina,

105 2010; Velázquez-Abunader et al., 2013; Gamboa-Álvarez et al., 2015; Markaida et al.,

106 2017). Each "alijo" had a global positioning system (GPS) to track the course and thus

107 measure the swept area. The initial and final times were recorded to standardize the

108 effective fishing effort in three hours and the sampling effort in five "alijos" per sampling

109 site per day. In each sampling site, the total number of octopuses captured $\left(N_{t}\right)$, the total

110 weight of the catch $(T W)$ and the individual weight of octopuses $\left(W_{i}\right)$ were recorded.

\section{Area of influence of sampling sites}

112 In order to have a better approach to the potential area of influence of each sampling site,

113 Thiessen (or Voroni) polygons were deployed (Brassel \& Reif, 1979), to calculate the area

114 of each polygon and, finally, obtain the representative area of each sampling site in relation

115 to the total sample area. Thiessen polygons and the area of each polygon were calculated

116 with the ArcMap 9.2 software (Sawatzky et al., 2009).

\section{Biomass assessment}

118 Four methods were used to calculate the $O$. maya biomass per research cruise: stratified

119 random method (Cochran, 1980; Scheaffer et al., 1987), swept area method (Pierce \&

120 Guerra, 1994), geo-statistical biomass model (Rivoirard et al., 2008), and an unpublished

121 method of weighted swept area, whose advantage is that it does not assume $a$ priori 
122 homogeneous distribution of the resource in the whole area, as the traditional swept area

123 method does (Pierce \& Guerra, 1994).

125 catch, which is classified by strata (Cochran, 1980). This method requires to calculate the

126 number of strata (expressed in $\mathrm{kg}$ ) by means of the Sturges rule (Nevárez-Martínez et al.,

127 2000) which calculates the number of intervals of the catch, starting from the minimum and

128 maximum catches recorded in each cruise. Equations to calculate biomass were the

129 following. The average counting (expressed in $\mathrm{kg}$ ) in the $i^{\text {th }}$ stratum $\left(\bar{y}_{i}\right)$ was:

$130 \quad \overline{\mathrm{y}}_{i}=\frac{1}{N} \Sigma^{i} y_{j i}$

131 The variance estimator for $\bar{y}_{i}$ :

$132 \hat{V}\left(\overline{\mathrm{y}}_{i}\right)=s_{i}^{2}=\frac{1}{N_{i}} \sum_{j=1}^{L}\left(y_{j i}-\overline{\mathrm{y}}_{i}\right)^{2}$

133 The estimator of the total size of the population expressed in $\mathrm{kg}$ :

$134 N \bar{y}_{s t}=\sum_{i=1}^{L} N_{i} \bar{y}_{i}$

135 The variance estimator for the total population size $\hat{V}\left(N \bar{y}_{s t}\right)$ :

$136 \hat{V}\left(N \bar{y}_{s t}\right)=\sum_{i=1}^{L} N_{i}^{2}\left(\frac{N_{i}-n_{i}}{N_{i}}\right)\left(\frac{S_{i}^{2}}{n_{i}}\right)$

137 The confidence interval $(p=0.95)$ for the population size:

$138 N \bar{y}_{s t} \pm 2 \sqrt{\sum_{i=1}^{L} N_{i}^{2}\left(\frac{N_{i}-n_{i}}{N_{i}}\right)\left(\frac{S_{i}^{2}}{n_{i}}\right)}$

139 where $N_{i}$ is the total number of sampled units $\left(\mathrm{km}^{2}\right)$ in the $i^{\text {th }}$ stratum, $L$ is the number of

140 strata, $n_{i}$ is the number of sampling units $\left(\mathrm{km}^{2}\right)$ in the $i^{\text {th }}$ stratum, $y_{i}$ is the average weight in

141 the $i^{\text {th }}$ stratum, and $S_{i}^{2}$ is the variance of the counting in the $i^{\text {th }}$ stratum. 
142 The swept area method considers the catch in weight (biomass) obtained from the

143 area swept by the "alijos", assuming a homogeneous distribution of the resource in the

144 study zone, with a single estimate for the whole area sampled.

145 Total biomass $\left(B_{T}\right)$ was calculated with the next equation (Pierce \& Guerra, 1994):

$146 \quad B_{T}=\sum_{i=1}^{n}\left(Y_{t} \frac{A_{t}}{a_{t}}\right)$

147 with variance:

$148 \hat{V}\left(B_{T}\right)=\sum_{i=1}^{n}\left(\frac{A_{t}^{2} m_{t} S_{t}^{2}}{a_{t}^{2}}\right)$

149 where $Y_{t}$ is the total catch in the study area, $A_{t}$ is the total area of study, $a_{t}$ is the cumulated 150 area swept of the five "alijos", $S_{t}^{2}$ is the variance of the total catch in the study area, $m_{t}$ is 151 the number of fishing trials and $\hat{V}\left(B_{T}\right)$ is the variance of the total biomass. In this case, $a_{i}$ 152 represented the area swept by the $i^{\text {th }}$ "alijo". Therefore, the total swept area $a_{t}$ (expressed in $153 \mathrm{~km}^{2}$ ) for each fishing trial was calculated as:

$154 a_{t}=\sum_{i=1}^{5} a_{i}$

$155 a_{i}$ was calculated with the following equation:

$156 a_{i}=D_{i} \times L J_{i}$

157 where $D_{i}$ is the distance traveled by the $i^{\text {th }}$ "alijo", obtained from the track recorded by the

158 GPS and $L J_{i}$ is the length between the extreme tips of the $i^{\text {th }}$ "alijo' s" bamboo poles $\left(L J_{i}=8\right.$

$159 \mathrm{~m})$. Finally, total abundance $\left(N_{T}\right)$ for each cruise ship was calculated with the equation:

$160 \quad N_{T}=\frac{B_{T}}{T W}$ 
161 where $\overline{T W}$ is the average weight of the octopus as obtained from the biological sampling.

162 For the estimation of $B_{T}$ the assumptions were the same as for the swept area method

163 (details of the method are contained in Csirke 1989).

In order to estimate the biomass using the geo-statistical biomass model, we

165 proceeded to calculate the catch per unit of area (CPUA, expressed in number of octopuses

166 per $\mathrm{km}^{2}$ ), obtained by dividing the number of octopuses captured by the corresponding area

167 at each sampling site. The spatial correlation of CPUA was calculated by means of

168 omnidirectional empiric variograms, which measures the correlation between the variance

169 generated by all the differences of the data pairs separated by a distance previously

170 established, with that distance (h) (Hernández-Flores et al., 2015). Thereafter, a kriging

171 interpolation technique was applied to obtain the densities throughout the interpolation

172 nodes between the neighboring values (Cressie, 1992) and produce a spatial structure that

173 depends on the spatial arrangement of the population (Webster \& Oliver, 2007).

174 The empirical variograms were obtained with the equation:

$175 \quad(h)=\frac{1}{2 N(h)} \sum_{i=1}^{N(h)}\left[C\left(x_{i}\right)-C\left(x_{i}+h\right)\right]^{2}$

176 where $\gamma(h)$ is the variance for $h$ distance, $N(h)$ is the number of paired observations

177 separated by distance $h, C\left(x_{i}\right)$ is the CPUA observed at site $x_{i}$ and $C\left(x_{i}+h\right)$ is the CPUA

178 observed at any another site separated $h$ distance from site $x_{i}$. The obtained interpolations

179 were divided into CPUA intervals, obtaining an average value for the $i^{\text {th }}$ interval $\left(\overline{C P U A}_{i}\right)$.

180 The total abundance of the $i^{\text {th }}$ interval $(\mathrm{Ni})$ was obtained from multiplying the $\left(\overline{\mathrm{CPUA}}_{i}\right)$ by

181 total area covered by the $i^{\text {th }}$ interval, so the total abundance $\left(N_{T}\right)$ was obtained with the

182 equation: 
$183 \quad N_{T}=\sum_{i=1}^{n} \overline{C P U A}_{i} \times A_{i}$

184 and the biomass was obtained with the equation:

$185 B_{T}=N_{T} \overline{T W}$

186 The weighted swept area method, proposed in this study, consisted in analyzing the catches

187 registered by the five "alijos" that operated at every $i^{\text {th }}$ sampling site $\left(a_{t}\right)$ as the only datum

188 for that site. The total biomass was obtained by adding the individual biomass estimated in

189 each sampling site. Thus, the biomass was obtained with the next equation:

$190 B_{T}=\sum_{i=1}^{n} Y_{i}\left(\frac{A_{i}}{a_{i}}\right)$

191 With standard deviation:

$192 \widehat{S D}\left(B_{T}\right)=\sqrt{\sum\left(Y_{i}-\bar{Y}\right)^{2}}\left(\frac{A_{i}}{a_{i}}\right)$

193 where $Y_{i}$ is the total catch in the $i^{\text {th }}$ stratum, $Y$ is the average catch in the study area, $A_{i}$ is the

194 total area in the $i^{\text {th }}$ stratum, $a_{i}$ is the swept area in that stratum and $\widehat{S D}\left(B_{T}\right)$ is the standard

195 deviation of total biomass. Abundance was again calculated with equation 10.

For the interpretation of the weighted swept area method, it was necessary to

197 modify the assumption of densities homogeneity, so the total catch $Y_{i}$ of the distribution

198 area $A_{i}$ was specific for every sampling site. Another assumption was that each "alijo" had

199 the same probability of catching the octopus at a fixed radius of action such that the

200 sampling effort could be extrapolated to a constant area $a$. The swept area is considered as

201 the area covered by each "alijo" drifting at each sampling site. Finally, within the area, each 
202 unit of sampling effort has the efficiency to catch octopuses every moment only a fraction

203 of the population.

\section{Spatial distribution pattern}

205 To describe the type of pattern distribution of $O$. maya, the equation proposed by Guerra

206 (1981) was modified. The average probability of octopus presence per sampling site was

207 estimated, as well as the type of distribution. Then, the parameters $p$ and $k$ of the negative

208 binomial distribution were estimated.

$209 P(x / k)=\left(\frac{k(k+1)(k+2) \ldots(k+x-1)}{x !}\right) p^{x} q^{k}$

210 To demonstrate if octopus's distribution was random (i.e. homogeneous in the study

211 area) or if it formed patches (i.e. aggregate in some places), a simple random distribution

212 was created assuming the negative binomial distribution. According to this method, the

213 estimation of the parameter of the negative binomial distribution $(k)$ could be: $K_{l}=\bar{x}^{2} / \mathrm{S}^{2}-$

$214 \bar{x}$, testing some of the following conditions: if $\bar{x}$ value was low, then $K / \bar{x}>6$, if $\bar{x}$ was high

215 then $K>13$, and if $\bar{x}$ value was moderate then $\left(\frac{(k+\bar{x})(k+2)}{\bar{x}}\right) \geq 15$.

216 If none of these conditions occurs, $K_{l}$ is inadequate then, it is calculated with:

$217 \quad K_{2} \log _{10}\left(1+\frac{\bar{x}}{K_{2}}\right)=\log _{10}\left(\frac{N}{f_{0}}\right)$

218 in any case, $p=\bar{x} / K \quad(19)$

219 Once the parameters were calculated, to verify if the distribution was in patch, a

220 goodness-of-fit test was applied between the distribution function of the total sample and

221 the theoretical negative binomial distribution (Zar, 1999). 


\section{Results}

\section{Biomass}

224 The coefficient of variation (CV) for the biomass obtained with the four methods was lower

225 for the cruise ship of May-June $(\mathrm{CV}=0.12)$ and higher for January $(\mathrm{CV}=0.26)$. The areas

226 of influence for each sampling site determined by the Thiessen polygons ranged from 60 to

$227940 \mathrm{~km}^{2}$ with an average of $242 \mathrm{~km}^{2}$. The lower biomass was calculated for the cruise ship

228 of May-June $(47.3 \pm 6.8 \mathrm{t})$, while the highest was estimated for December $(141.22 \pm 12.7 \mathrm{t})$

229 (Table 1). Of the four models, the geo-statistical biomass model consistently resulted in the

230 lowest values in the four cruise ships, while the other three methods produced results more

231 alike. This is so because geostatistic analysis assumes a heterogeneous distribution pattern

232 generated by the parameters of the semivariogram, through which the minimum size of

233 each pixel is calculated. On the other hand, the other methods extrapolate the average

234 values of biomass to units of areas wider than those of the geostatistical model. The

235 precision of the geostatistic method will depend on how well it represents the real spatial

236 distribution of the abundance within a reduced coverage relative to the other methods. The

237 geo-statistical biomass model estimations were between $22 \%$ and $47 \%$ lower than that of

238 the other models (Table 1). Similar pattern was observed for densities; however, the

239 increases from one month to the next were not as marked as in biomass. The highest

240 densities were recorded in the cruise ships of May-June and July 2016 (13.4 and 20.5

241 octopus $\mathrm{km}^{2}$, respectively), while the lowest densities were observed in the cruise ships of

242 May-June 2016 and January 2017 (7.6 and 10.3 octopus km² , respectively). Similarly, the

243 geo-statistical biomass model resulted in the lowest values of density in the four cruise

244 ships and the weighted swept area method produced the highest values (Table 1). 


\section{Distribution}

246 The value of the parameters $p$ and $k\left(k_{2}=2, p=0.5\right)$ of the negative binomial distribution

247 showed that $O$. maya presented a patchy distribution (Figure 2), suggesting that the

248 abundance increases according to distance in an area specific and then begins to decrease at

249 higher distances. This is plausible if we consider that the study area deepens as the latitude

250 increases. So, in the shallower water the abundance increases.

251 The cruises made before the fishing season (May-June and July 2016) recorded the

252 highest densities and abundances in the south and southwest of the study area (Figure 3).

253 The octopuses displayed a heterogenous distribution throughout the study area with lower

254 CPUE overall in the cruises carried out at the end of the fishing season (December 2016

255 and January 2017); nevertheless, areas of aggregation continued appearing in the analysis,

256 although with lower densities than in May-June and July of 2016 (Figure 3).

\section{Discussion}

258 Many cephalopod fisheries are managed through total allowable catches, which are usually

259 based on the evaluation of the biomass before the start of each fishing season (Nevárez-

260 Martinez et al., 2000). This is the case of $O$. maya, although frequently the TAC is

261 exceeded in some seasons (Jurado-Molina, 2010). This is mainly due to their reproductive

262 strategies that in many cases are semelparous, as well as their short longevity and rapid

263 growth. These biological characteristics make the structure of populations to consist of

264 intra-annual cohorts that are replaced year after year (Hernández-Herrera et al., 1998;

265 Arreguín-Sánchez et al., 2000). That is why it is important to calculate the biomass of

266 exploited cephalopods at different moments during the fishing season, since this will reveal 
267 the stock size, recruitment periods and the time when the biomass increases (i.e. stock

268 reduction analysis and proportional escapement analysis) (Rosenberg et al., 1990).

270 carried out in the north eastern zone of the Campeche Bank between $30 \mathrm{~m}$ and $60 \mathrm{~m}$ depth.

271 Most techniques to calculate biomass use catch and fishing effort data, which are not

272 always available as is in the case of $O$. maya fishery. However, this study used a systematic

273 sampling design, independent of the fishery, which has the advantage of covering a larger

274 distribution area, controlling the sampling effort (Pierce \& Guerra, 1994; Hernández-Flores

275 et al., 2015).

276 Given that there are no previous studies on the biomass of octopus for the fraction

277 of the population that occurs more than $30 \mathrm{~m}$ deep in the study area, this study used four

278 methods to analyse the data, with particular characteristics and assumptions. Our results

279 show that differences in the biomass estimates from each of the four methods $(\mathrm{CV}<26.5 \%$

280 per cruise) could be biologically relevant and important consideration for managers (Pierce

$281 \&$ Guerra, 1994). These differences in the results could be related to factors such as the

282 distribution pattern of the resource and the sampling design; for example, in the swept area

283 method, the weighted swept area method and the geo-statistical biomass method, the

284 distance between sampling sites is key so as not to exceed the area of extrapolation per

285 sampling site, while in the stratified method the number of intervals is key in the estimate.

286 It is instructive to apply the Sturges rule from the start of the analysis (Labastida, 1991).

287 The assumption of heterogeneous distribution of the resource is perfectly applicable to the

288 benthic organisms that remain in the same habitat as long as the conditions are favourable,

289 and that present a patchy distribution, such as was the case of $O$. maya. 
In resources such as the jumbo squid from the Gulf of California, biomass has been

291 calculated through the stratified random method and the swept area method, showing

292 significant differences in the results of both (Nevárez-Martinez et al., 2000). These

293 discrepancies were attributed to the type of stratification used in each method, since the

294 randomized method stratified the catch data, while the swept area method stratified the data

295 spatially (Nevárez-Martínez et al., 2000). Therefore, in addition to the method, it is

296 important that fisheries managed with total allowable catches apply the precautionary

297 approach considering the most conservative result (Nevárez-Martínez et al., 2000), which

298 in the case of the O. maya should be applied when estimating in the fishing grounds. This

299 precautionary approach should be applied in the areas with the greatest fishing effort.

300 The distribution of the $O$. maya has not been thoroughly studied; most studies have

301 covered the immediately coastal zone with the highest concentration of octopuses between

3020 and $30 \mathrm{~m}$ depth. Some studies have suggested that the $O$. maya has a heterogeneous

303 distribution in the shallow waters of the Campeche Bank ( $<30 \mathrm{~m}$ depth) (Solís-Ramírez \&

304 Chávez, 1986; Gamboa-Álvarez et a., 2015) as a response to changes in the environment

305 like the effect of the wind during winter or the type of substratum. Cephalopods are

306 organisms highly sensitive to environmental changes, so they can carry out active

307 migrations in search of favourable conditions to continue their life cycle (Pierce et al.,

308 2008). In this study, although in general, O. maya showed a patchy distribution, during the

309 December and January cruises it was more randomly, with few aggregations of low CPUA

310 values. This type of distribution has been reported by Gamboa-Álvarez et al. (2015) in the

311 shallow waters of the Yucatan Peninsula, probably due to the dynamics of the ocean in the

312 region that includes significant changes in temperature (Enriquez et al., 2010), which is a 
313 key factor for the biological processes of the species (Ángeles-González et al., 2017). In

314 this sense, it has been reported that $O$. maya has a low capacity to adapt to high variations

315 of temperature, producing a significant negative impact on its survival rate and abundance

316 (Noyola et al., 2013). As shown by Hermosilla et al. (2011), there is a negative correlation

317 between sea bottom temperature and abundance of $O$. vulgaris in the Mediterranean Sea. In

318 consequence, temperature changes limit octopus distribution in deeper waters, which seems

319 to be the origin of the distribution observed in this study.

As occurs in other cephalopods like inshore squids and some octopod species

321 including the common octopus ( $O$. vulgaris), . maya shows a great plasticity in its life

322 cycle, which gives it a great ability to adapt to the prevailing conditions where it lives (Pecl

323 and Jackson 2008; Ramos et al., 2008; Otero et al., 2009), but there are no studies that

324 correlate environmental variables with the biomass and distribution of $O$. maya. Therefore,

325 it seems that the home range of this species should be well specified, which could be a

326 priority for future research. However, spatial differences in population structure of this

327 species have been evaluated. Authors such as Velázquez-Abunader et al. (2013) indicated

328 that the landings of the medium-scale fleet (which fishes in deeper waters than the small-

329 scale fleet) were mainly composed of large organisms, so that the stratum of the population

330 that occurs in deeper waters could be composed mostly of mature individuals of the

331 spawning stock. Thus, this fraction of the stock could contribute significantly to the

332 recruitment of the entire population, even to the fraction that is currently exploited $(<30 \mathrm{~m}$

333 depth), so it is suggested to avoid the exploitation of this resource in deeper areas. In

334 addition, the methods used in this study could be applied to calculate the biomass in the

335 most intense fishing areas, as long as a stratified sampling design is applied. Therefore, 
336 future work should make an assessment of the biomass and distribution of $O$. maya in

337 shallower fishing areas.

338 Acknowledgment

339 The authors thank to the Federación de Sociedades Cooperativas de la Industria Pesquera

340 del Centro y Oeste del estado de Yucatán, SC de RL for the logistical support and with the

341 boat to carry out the cruises. To Jesús Miguel Soto Vázquez for his support in the field

342 work. Thanks are also due to Mr. Babatunde O. Musa for proofreading.

$343 \quad$ Financial support

344 The results of this study were obtained as part of the project Distribución, reproducción,

345 biomasa y patrones de movimiento del pulpo común Octopus vulgaris Cuvier, 1797 en la

346 costa de Yucatán with financial support of the Consejo Nacional de Ciencia y Tecnología

347 (grant number 237057).

348 References

349 Ángeles-González, L.E., Calva, R., Santos-Valencia, J., Avila-Poveda, O.H., Olivares,

350 A., Diaz, F., and Rosas, C. (2017). Temperature modulates spatio-temporal

351 variability of the functional reproductive maturation of Octopus maya (Cephalopoda)

352 on the shelf of the Yucatan Peninsula, Mexico. Journal of Molluscan Studies 83, 280-

353288.

354 Arreguín-Sánchez, F., Solís-Ramírez, M.J., and de la Rosa, M.E.G. (2000). Population

355 dynamics and stock assessment for Octapus maya (Cephalopoda: Octopodidae)

356 fishery in the Campeche Bank, Gulf of Mexico. Revista de Biología Tropical 323-

$357 \quad 331$.


Avila-Poveda, O.H., Koueta, N., Benítez-Villalobos, F., Santos-Valencia, J., and Rosas,

Brassel, K.E., and Reif, D. (1979). A procedure to generate Thiessen polygons. implications for fisheries management. Molluscan Research 36, 29-44.

Cabrera-Vázquez, Ramos-Miranda, J., and Salas, S. (2012). Análisis de la Estructura Geographical Analysis 11, 289-303.

Poblacional del Pulpo Rojo (Octopus maya) en la Península de Yucatán, México. Proceedings of the 64th Gulf and Caribbean Fisheries Institute October 31 November 5, 2011 Puerto Morelos, Mexico 64, 481-485.

Cochran, W.G. (1980). Técnicas de muestreo (CECSA). Compañia Editorial Continental. México. 513 p. ISBN: 9682601517

Cressie, N. (1992). Statistics for spatial data. Terra Nova 4(5), 613-617.

Csirke, J. (1989). Introducción a la dinámica de poblaciones de peces (Documento Técnico de Pesca No. 192) (p. 82). Rome, FAO.

Diario Oficial de la Federación. (2016). Norma Oficial Mexicana NOM008SAG/PESC2015, para ordenar el aprovechamiento de las especies de pulpo en las aguas de jurisdicción federal del Golfo de México y Mar Caribe. 13 de abril de 2016. SAGARPA. Ciudad de México.

Duarte, J.A., Hernández-Flores, A., Salas, S., and Seijo, J.C. (2018). Is it sustainable fishing for Octopus maya Voss and Solis, 1966, during the breeding season using a bait-based fishing technique? Fisheries Research 199, 119-126.

Enriquez, C., Mariño-Tapia, I.J., and Herrera-Silveira, J.A. (2010). Dispersion in the Yucatan coastal zone: Implications for red tide events. Continental Shelf Research $30,127-137$. 
382 Gamboa-Álvarez, M.Á., López-Rocha, J.A., and Poot-López, G.R. (2015). Spatial analysis of the abundance and catchability of the red octopus Octopus maya (Voss and Solis-Ramírez, 1966) on the continental shelf of the Yucatán peninsula, México. Journal of Shellfish Research 34, 481-492.

Guerra, A. (1981). Spatial distribution pattern of Octopus vulgaris Cuvier. Journal of Zoology of London, 195(1): 133-146.

Hernández-Flores, A., Condal, A., Poot-Salazar, A., and Espinoza-Mendez, J. (2015). Geostatistical analysis and spatial modeling of population density for the sea cucumbers Isostichopus badionotus and Holothuria floridana on the Yucatan Peninsula, Mexico. Fisheries Research 172, 114-124.

Hernández-Herrera, A., Morales-Bojórquez, E., Cisneros-Mata, M., NevárezMartínez, M., and Rivera-Parra, G. (1998). Management strategy for the giant squid (Dosidicus gigas) fishery in the Gulf of California, Mexico. CalCOFI Report $39,212-218$.

Hermosilla, C., Rocha, F., and Valavanis, V.D. (2011). Assessing Octopus vulgaris distribution using presence-only model methods. Hydrobiologia, 670(1), 35-47.

Jereb, P., Roper, C.F.E., Norman, M.D. y Finn, J.K. (2014). Cephalopods of the world. An annotated and illustrated catalogue of cephalopod species known to date. Volume Rome. 4(3), 382 pp. ISSN 10120-8682

Jurado-Molina, J. (2010). A Bayesian framework with implementation error to improve the management of the red octopus (Octopus maya) fishery off the Yucatán Peninsula. Ciencias Marinas 36, 1-14. 
Lima, F.D., Berbel-Filho, W.M., Leite, T.S., Rosas, C., and Lima, S.M. (2017). Occurrence of Octopus insularis Leite and Haimovici, 2008 in the Tropical Northwestern Atlantic and implications of species misidentification to octopus fisheries management. Marine Biodiversity 47, 723-734.

Markaida, U., Méndez-Loeza, I., and Rosales-Raya, M.L. (2017). Seasonal and spatial trends of Mayan octopus, Octopus maya, population dynamics from Campeche, Mexico. Journal of the Marine Biological Association of the United Kingdom 97,

Nevárez-Martínez, M.O., Hernández-Herrera, A., Morales-Bojórquez, E., Balmori-

Pebesma, E.J., and Bivand, R.S. (2005). Classes and methods for spatial data in R. R News

Otero, J., González, A.F., Guerra, A., and Álvarez-Salgado, X.M. (2009). Efectos do Noyola, J., Caamal-Monsreal, C., Díaz, F., Re, D., Sanchez, A., and Rosas, C. (2013). Ramírez, A., Cisneros-Mata, M.A., and Morales-Azpeitia, R. (2000). Biomass and distribution of the jumbo squid (Dosidicus gigas; d'Orbigny, 1835) in the Gulf of California, Mexico. Fisheries Research 49, 129-140.

Thermopreference, tolerance and metabolic rate of early stages juvenile Octopus maya acclimated to different temperatures. Journal of Thermal Biology 38, 14-19.

425 Pecl, G.T., and Jackson, G.D. (2008). The potential impacts of climate change on inshore 426 squid: biology, ecology and fisheries. Reviews in Fish Biology and Fisheries, 18(4), 373-385. 
428 Pierce, G.J., and Guerra, A. (1994). Stock assessment methods used for cephalopod $429 \quad$ fisheries. Fisheries Research 21, 255-285.

430 Pierce, G.J., Valavanis, V.D., Guerra, A., Jereb, P., Orsi-Relini, L., Bellido, J.M., 431 Katara, I., Piatkowski, U., Pereira, J., Balguerias, E., and others. (2008). A review of cephalopod-environment interactions in European Seas. Hydrobiologia $612,49-70$.

R Core Team. (2017). R: A Language and Environment for Statistical Computing. R Foundation for Statistical Computing, Vienna, Austria.

Ramos, J. E., Pecl, G. T., Moltschaniwskyj, N. A., Strugnell, J. M., León, R. I., \& Semmens, J. M. (2014). Body size, growth and life span: implications for the polewards range shift of Octopus tetricus in south-eastern Australia. PLoS One, 9(8). e103480.

Rivoirard, J., Simmonds, J., Foote, K., Fernandes, P., and Bez, N. (2008). Geostatistics for estimating fish abundance. John Wiley \& Sons.

442 Rosenberg, A., Kirkwood, G., Crombie, J., and Beddington, J. (1990). The assessment of stocks of annual squid species. Fisheries Research 8, 335-350.

444 Salas, S., Cabrera, M., Palomo, L., Bobadilla, F., Ortega, P., and Torres, E. (2008). Plan de manejo y operación del comité de administración pesquera de escama y pulpo. Informe Final. Cinvestav IPN Unidad Mérida, Mexico.

449 forcing and currents in a tropical coral reef system. Estuarine, Coastal and Shelf $450 \quad$ Science 100, 102-112. 
451 Sawatzky, D., Raines, G., Bonham-Carter, G., and Looney, C. (2009). Spatial Data 452 Modeller (SDM): ArcMAP 9.2 geoprocessing tools for spatial data modelling using

Scheaffer, R.L., Mendenhall, W., and OTT, O. (1987). Elementos de Muestreo (Vol. 33). Grupo Editorial Iberoamérica. $845-854$.

463 Webster, R., and Oliver, M.A. (2007). Geostatistics for environmental scientists. John $464 \quad$ Wiley \& Sons.

465 Zar, J.H. (1999). Biostatistical analysis. Pearson Education India. 


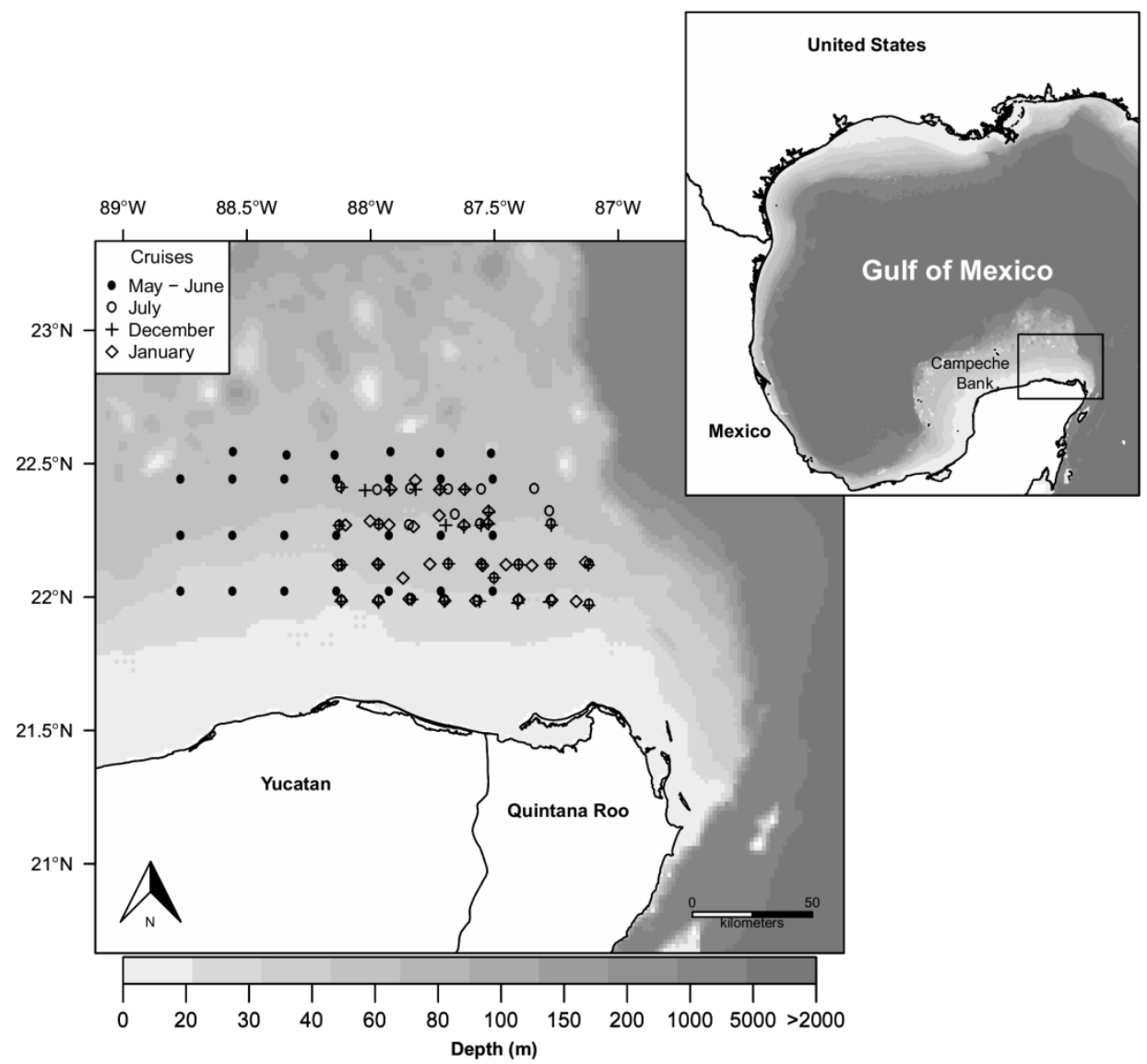

Study area for fishing of the Red octopus (Octopus maya) to the East of Campeche Bank, Mexico.

$182 \times 173 \mathrm{~mm}(300 \times 300 \mathrm{DPI})$ 


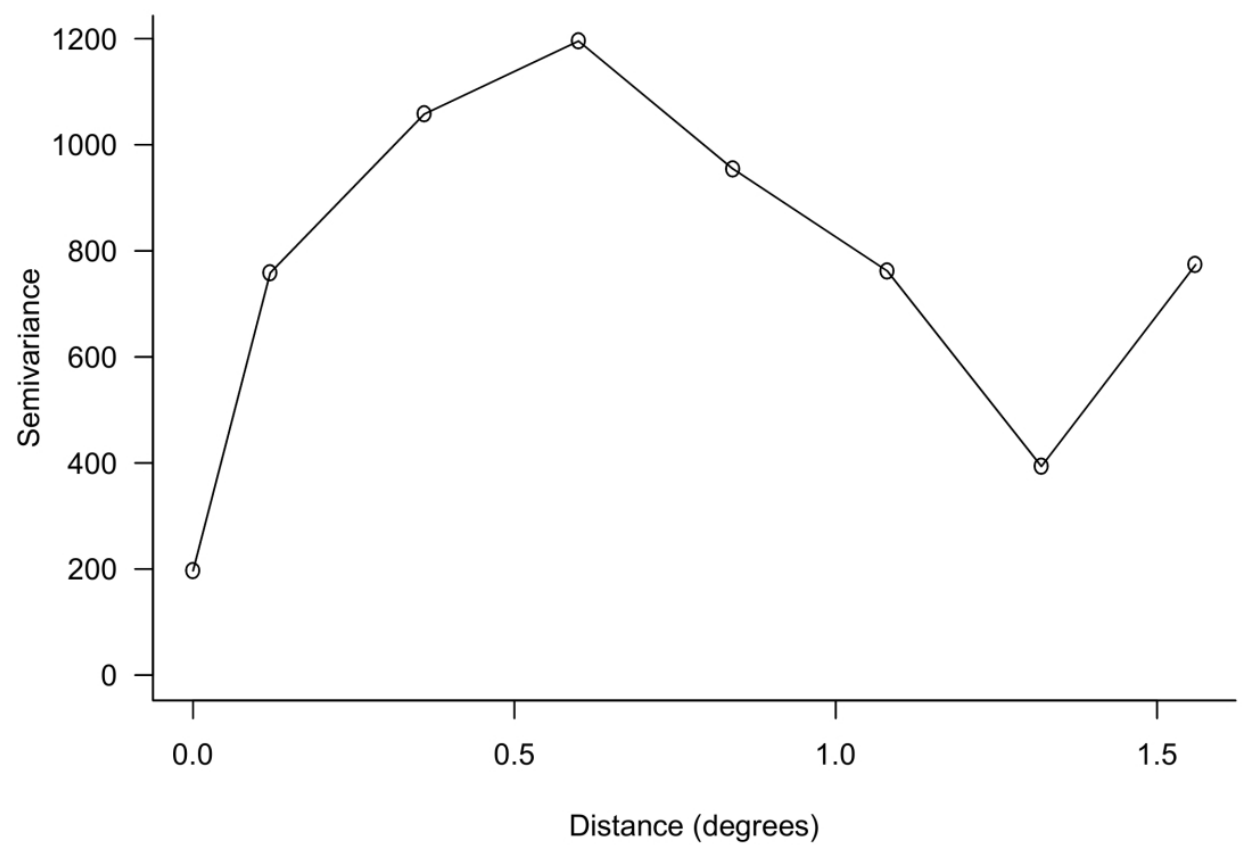

Semivariogram analysis of the abundances (CPUA; Org. $/ \mathrm{km}^{2}$ ) of the Red octopus (Octopus maya) in the north eastern Campeche Bank, Mexico. The behavior indicated a grouped type distribution

$185 \times 144 \mathrm{~mm}(300 \times 300 \mathrm{DPI})$ 

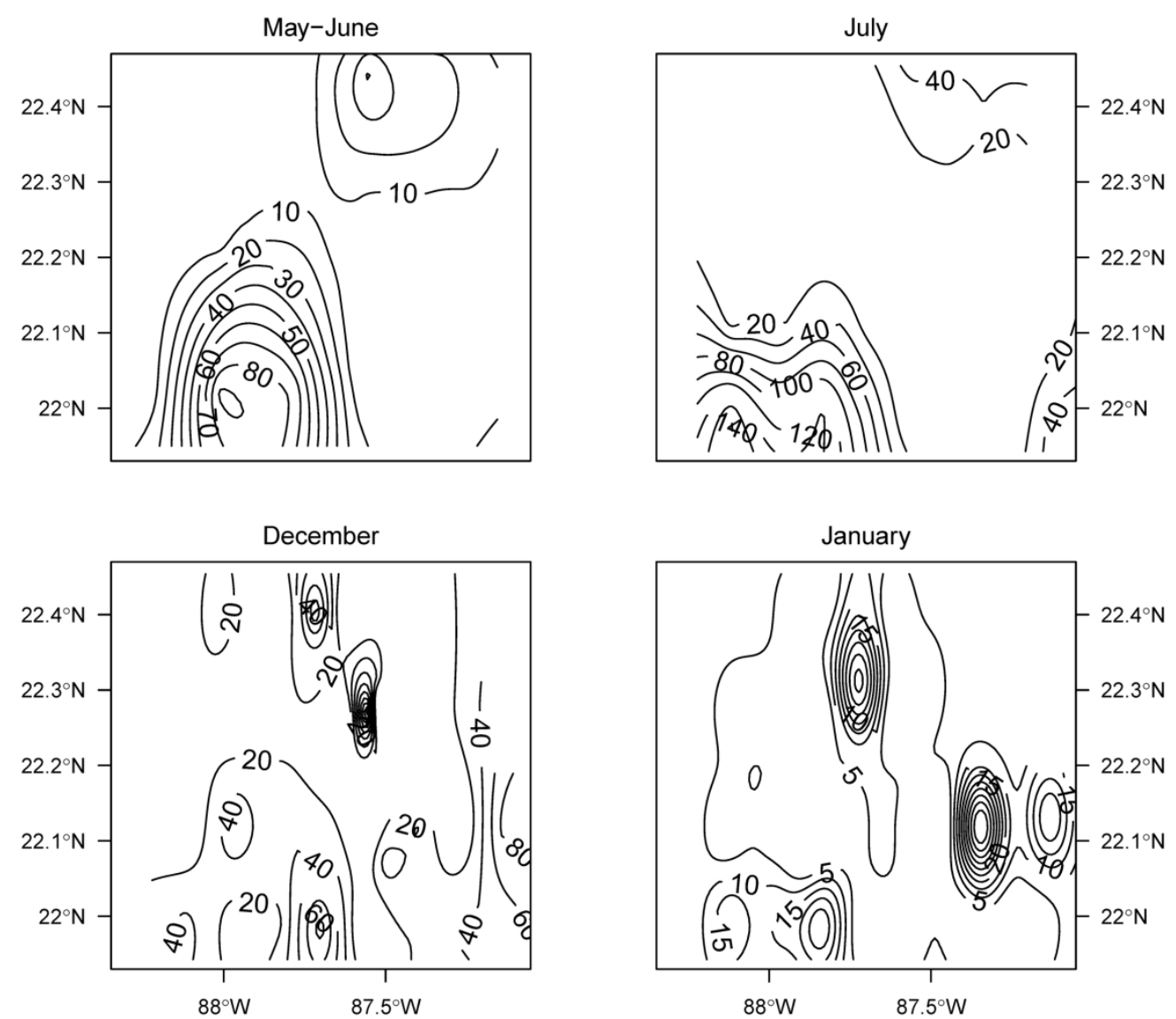

Spatiotemporal distribution of the Catch Per Unit Area (CPUA: Org. $/ \mathrm{km}^{2}$ ) of the Red octopus (Octopus maya) in the north eastern Campeche Bank, Mexico

$192 \times 168 \mathrm{~mm}(300 \times 300 \mathrm{DPI})$ 
Table 1. Estimated values of the biomass per cruise \pm standard error (SE) and the density \pm standard error (SE) of the Red octopus (Octopus maya) in the north eastern Campeche Bank. The biomasses were standardized to a total area of $5000 \mathrm{~km}^{2} . \mathrm{CV}$ : coefficient of variation of the estimates by cruise of the four methods.

\begin{tabular}{rrrrr}
\hline \multicolumn{1}{c}{ Method } & $\begin{array}{c}\text { Biomass } \\
\text { (tonnes) }\end{array}$ & \pm SE & $\begin{array}{c}\text { Density } \\
\text { (Org./km } \mathbf{k}^{2}\end{array}$ & $\pm \mathbf{S E}$ \\
\hline May-June 2016 CV $=12.5 \%$ & $\mathrm{CV}=12.5 \%$ & \\
Stratified & 47.7 & 1.0 & 9.5 & 0.2 \\
Swept area & 50.0 & 8.8 & 9.7 & 1.7 \\
Geostatistic & 39.0 & 8.6 & 7.6 & 1.6 \\
Weighted & 52.8 & 9.0 & 10.3 & 1.7 \\
July 2016 CV $=18.3 \%$ & $\mathrm{CV}=17.7 \%$ & \\
Stratified & 103.2 & 0.9 & 19.8 & 0.2 \\
Swept area & 94.8 & 12.5 & 18.4 & 2.4 \\
Geostatistic & 68.3 & 12.5 & 13.4 & 2.4 \\
Weighted & 105.6 & 15.3 & 20.5 & 2.9 \\
December 2017 & $\mathrm{CV}=19.3 \%$ & $\mathrm{CV}=19.5 \%$ & \\
Stratified & 149.5 & 14.1 & 22.5 & 2.1 \\
Swept area & 161.1 & 13.7 & 24.0 & 2.0 \\
Geostatistic & 100.8 & 10.4 & 15.0 & 1.5 \\
Weighted & 153.4 & 12.6 & 22.9 & 1.9 \\
January 2017 & CV $=26.3 \%$ & $\mathrm{CV}=25.4 \%$ & \\
Stratified & 71.1 & 14.5 & 10.2 & 2.0 \\
Swept area & 70.0 & 9.9 & 9.5 & 1.4 \\
Geostatistic & 37.7 & 9.6 & 5.4 & 1.3 \\
Weighted & 70.9 & 11.2 & 9.6 & 1.5 \\
\hline
\end{tabular}

